\title{
Identification of Cancer Stem Cells in Human Pancreatic Cancer, a Small Population with High Tumorigenic Activity and Chemotherapy Resistance
} Masahide Kashiwagi* and Hideyuki Tanaka

Pharmaceutical Research Division, Takeda Pharmaceutical Company Limited, Japan

\begin{abstract}
Small populations of pancreatic cancer cells from Patient Derived Xenografts (PDXs) were demonstrated to be highly tumorigenic and chemotherapy resistant. The cancer cells isolated from the xenograft tumor tissue were sorted by the previously reported "Cancer Stem Cell" (CSC) markers and tested their tumorigenic activity in the limiting dilution assay by inoculating into the immuno-deficient NOD/scid mice subcutaneously. The varied correlation between the CSC marker expression and the tumorigenic activity in the NOD/scid mice among the different PDXs indicates that the CSC markers of the individual pancreatic tumor patients could be different each other. Only a part of PDX tumor samples among the six examined could show a tight correlation between the tumor initiating activity and the selectively higher expression of cell surface markers CD24, CD44 and CD133. We also demonstrated that CD133/CD44 double positive population from the one PDX shows superior tumorigenic activity and gemcitabine treatment resistance. To illuminate the characteristically expressed genes which allow them to have tumorigenic activity and chemotherapy resistance, the CD133/CD44 double positive CSC faction was subjected to the gene expression analysis. Prominently higher expression of epiregulin (11.1-fold increase compared to the double negative population), interleukin-8 and CXCL5 (8.5- and 8.0-fold increases, respectively) were observed in the CSC fraction. These gene signatures of CSC suggest several key molecular mechanisms playing important roles in CSC biology and having possibilities as drug targets for CSC therapy.
\end{abstract}

Keywords: Pancreatic cancer; Cancer stem cell; Tumor initiating cell; Drug resistance; Patient derived xenograft

\section{Introduction}

Current radio- and chemotherapies are efficacious to the bulk of cancer cells, but are scarcely able to eliminate the particular population of the cancer cells so called Cancer Stem Cells (CSCs) in the tumor tissue, which are protected from anti-cancer therapies by resistant mechanisms [1]. Survived CSCs are believed to cause tumor recurrence and distant metastasis, which result in poor prognosis. The recurrent tumors sometimes become more malignant compared to the primary tumor and turn to be resistant to radio- and chemotherapies applied as the primary treatment, which makes the prognosis for tumor patients poorer. Thus, the existence of CSCs could provide an explanation for many therapeutic failures and highlight new directions for more effective cancer therapy.

A series of recent publications has revealed that only a small population among the whole cancer cells in a tumor tissue has a tumor initiating activity initially in hematologic cancer [2] and later in solid tumors, such as breast cancer [3], brain tumor [4], colorectal cancer [5], lung cancer [6] and prostate cancer [7], and possibly plays an important role for metastasis or recurrence of the tumor. The cancer cells with the specific cell surface antigen were isolated from the tumor tissue by fluorescent activated cell sorter (FACS), and inoculated in an immunodeficient mouse such as a nude or a NOD/scid mouse in the extremely small numbers (e.g., 100 cells), giving rise to form a secondary tumor tissue with heterogeneous cellular contents just as same as the primary tumor tissue. The cancer cells with such tumorinitiating and multi-potent differentiation abilities have been referred as "Cancer Stem Cells" [8], demonstrating their increased resistance to X-ray irradiation and anti-cancer drugs [9]. The Cancer Stem Cells may survive in a tumor lump during radio- or chemotherapy, and cause the recurrence after the treatment. Namely targeting the Cancer Stem Cells allows us to develop more effective anti-cancer treatments than currently available ones. Further analysis in the cell biology of the
Cancer Stem Cells is highly expected to find a new molecular target for anti-cancer drug.

According to Li et al. [10], the pancreatic Cancer Stem Cells were identified in the clinical tumor tissue as the CD44, CD24 and EpCAM triple positive fraction, which was $0.2-0.8 \%$ of total cancer cells. The Cancer Stem Cells were able to form a tumor with tissue image same as the parental tumor when only 100 cells were inoculated to the NOD/ scid mouse subcutaneously. On the other hand, Hermann et al. reported that the pancreatic Cancer Stem Cells were enriched in CD133 positive cellular fraction [11]. Taking the above information into account, we tried to isolate the pancreatic Cancer Stem Cells from patient derived tumor xenografts.

\section{Material and Methods}

Balb/c-nu/nu mice (6-8) weeks old purchased from CLEA Japan (Tokyo, Japan), NOD/scid (NOD.CB17-Prkdcscid/J) mice were from Charles River Laboratories Japan (Yokohama, Japan) and housed at controlled temperature and humidity and a 12:12 h light-dark cycle under aseptic conditions.

Anti-CD133-PE conjugated antibody (Clone: AC133) was

*Corresponding author: Masahide Kashiwagi, Pharmaceutical Research Division, Takeda Pharmaceutical Company Limited, 26-1, Muraoka-Higashi 2-chome, Fujisawa, Kanagawa 251-8555, Japan, Tel +81-466-32-1917; Fax +81-466-29-5747; E-mail: masahide.kashiwagi@takeda.com

Received December 12 2016; Accepted December 21, 2016; Published December 26, 2016

Citation: Kashiwagi M, Tanaka H (2016) Identification of Cancer Stem Cells in Human Pancreatic Cancer, a Small Population with High Tumorigenic Activity and Chemotherapy Resistance. J Stem Cell Res Ther 6: 371. doi: 10.4172/2157-7633.1000371

Copyright: (c) 2016 Kashiwagi M, et al. This is an open-access article distributed under the terms of the Creative Commons Attribution License, which permits unrestricted use, distribution, and reproduction in any medium, provided the original author and source are credited. 
purchased from Miltenyi Biotech. Anti-CD44-PE or FITC conjugated antibody (Clone: IM7), anti-CD24-PE conjugated antibody and antiH2kd-FITC conjugated antibody were from Biolegend.

\section{Patient derived tumor xenografts}

Human pancreatic cancer xenografts PAN-02-JCK, PAN-04JCK, PAN-06-JCK, PAN-08-JCK, PAN-12-JCK and PAN-17-JCK were obtained from the Central Institute for Experimental Animals (Kawasaki, Japan). Since the patient derived samples were obtained from 1978 to 1990 without patient identification, the donor information was anonymized. These xenografts were maintained by sequential transplantation. Patient derived tumor was xenotransplantated into nude mice. The growing tumor was obtained from mice and cut into 3-4 $\mathrm{mm}$ fragments. The tumor fragments were implanted subcutaneously into the nude mice. The growing tumor size was measured using calipers and the tumor volume was estimated according to the following formulae: tumor volume $(\mathrm{mm})=\left(\right.$ Length $\left.\times \mathrm{Width}^{2}\right) / 2$.

\section{Cell isolation from tumor xenografts}

Tumor tissues obtained from xenografted mice were minced by razor blade into small pieces, enzymatically digested by approximately 10 times volume of Accutase (Innovate Cell Technologies Inc. San Diego, CA) for $30 \mathrm{~min}$ at $37^{\circ} \mathrm{C}$. The digested tumor tissue was further crashed by 20 slow strokes of pipetting with $1 \mathrm{ml}$ Gilson pipette, filtered by $100 \mathrm{um}$ cell strainer and centrifuged at $1,500 \mathrm{rpm}$ for $5 \mathrm{~min}$ at $4^{\circ} \mathrm{C}$. The cellular pellet was reconstituted by ice-cold Phosphate Buffered Saline (PBS) and centrifuged again to wash out remaining Accutase. The cellular pellet again was reconstituted in ice cold PBS to make cell suspension $\left(1 \times 10^{6}-10^{7}\right.$ cells $\left./ \mathrm{ml}\right)$ and mixed with Annexin $\mathrm{V}$ conjugated microbeads from Dead cell removal kit from Miltenyi Biotec. After $20 \mathrm{~min}$ incubation, the cell/microbeads mixture was processed by AutoMACS (Miltenyi Biotec) with depletion program. The flow through fraction contained tumor cells with more than $95 \%$ viability.

\section{Flow cytometeric analysis and cell sorting}

Aliquots (100 ul) of the cell suspension, containing $1 \times 10^{5}$ cells, were first reacted with human $\mathrm{FcR}$ blocking reagent to avoid antigen independent reaction and stained by fluorescent dye conjugated antibodies against CD133, CD44, CD24, H2Kd or isotype control antibodies. The cells were sorted by Becton Dickinson FACS Vantage SE with consistently yielding $>95 \%$.

\section{In vivo limiting dilution assay}

FACS sorted cellular fractions were serially diluted in RPMI1640 $10 \%$ FCS and inoculated with Matrigel (growth factor reduced, BD, Cat.\# 354230)/RPMI1640 10\% FCS(1:1) into NOD/scid (NOD.CB17Prkdcscid/J) mice subcutaneously. Tumor formation was observed for 1-4 months post injection. Each mouse was subjected to transplantation with various numbers of cancer cells on both sides of its back. The actual number of formed tumors was counted by observation of tumor lumps at the 8 sites in 4 mice in total ( 2 injected sites in each mouse). Tumor formations in individual mice were observed over one month for quick growing PAN-04 or four months for slow growing PAN-06. Tumor formation was judged to be positive if the lump in the inoculation site is more than $10 \mathrm{~mm}^{3}$. The putative frequency of tumor initiating cell was calculated according to the previously described method based on Poisson distribution [10].

\section{Gene expression analysis}

CD133+/CD44+ fraction $\left(5 \times 10^{6}\right)$ and CD133-/CD44- $\left(5 \times 10^{6}\right)$ fraction were separated by FACS and total RNA was extracted by RNeasy micro (Qiagen) and cRNA was prepared by GeneChip 3' IVT Express Kit and subjected to Affymetrix genechip human genome u133 plus 2.0 array. The data were analyzed through the use of IPA (Ingenuity Systems, www.ingenuity.com).

\section{Gemcitabine treatment for PAN-17-JCK xenografted mice}

Nude mice bearing PAN-17-JCK xenografted tumor with sizes of $300-600 \mathrm{~mm}^{3}$ were treated by gemcitabine $(125 \mathrm{mg} / \mathrm{kg}$, intraperitoneal administration) every 3 days for 2 weeks. One day after the final administration, the animals were sacrificed to isolate the tumor tissues. The isolated tumor tissue was digested and the tumor cells were stained by anti-CD133-PE conjugated antibody and anti-CD44-FITC conjugated antibody and subjected to FACS analysis as described in previous sections. Data are expressed as the mean $+\mathrm{SD}$. Statistically significant differences were determined by Student's $t$ test and defined as $\mathrm{P}<0.05$ or $\mathrm{P}<0.01$.

\section{Results}

\section{Expression of cell surface markers and cell sorting}

PAN-04-JCK, PAN-06-JCK, PAN-08-JCK, PAN-12-JCK, and PAN17-JCK contained positive expression of CD133, CD24 and CD44 on the cell surface while PAN-02-JCK only expresses CD44 among the tested markers. The pancreatic cancer cells stained by individual CSC markers were separated into positive and negative fractions by FACS and each fraction was confirmed to contain expected fraction. $\mathrm{H} 2 \mathrm{Kd}$ FITC recognizing murine stromal cells from the PDX tumor was eliminated from the cell collection (Figure 1).

\section{Tumorigenic activities of sorted fractions}

Cancer cells prepared from patient derived xenografts were sorted depending on cell surface marker expression and inoculated to NOD/ scid mice subcutaneously. Tumor formation rates are summarized in Table 1. Tumor formation was readily observed in shorter period less than one month for the cells from fast growing PAN-04-JCK xenograft, while the cells from slow growing PAN-06-JCK failed to form visible tumor tissues on most of the recipient animals within 4 months observation period. Tumor initiation activity in PAN-17-JCK xenograft showed tight correlation with expression levels of CD133 and CD44, which is consistent with the previous reports. In PAN-08JCK and PAN-12-JCK xenografts the cell populations with high CD133 expression had higher tumorigenic activity with a little correlation with CD44 expression. Tumor initiating activity in PAN-02-JCK showed negative correlation with CD44 expression. Finally PAN-04-JCK is highly tumorigenic even unsorted fraction and failed to show any significant correlation between the tumor initiating activity and the cell surface marker expression.

To further evaluate the tumor initiating potential of the CD133/ CD44 double positive cells from PAN-17-JCK, three groups of cells, unsorted, CD133/CD44 double positive, and double negative cell population (Figure 2), were subjected to an in vivo limiting dilution assay using NOD/scid mice. The frequency of tumor initiating cells in the PAN-17-JCK xenograft was estimated to be one in $2 \times 10^{3}$ unsorted cancer cells, one in $5 \times 10^{2} \mathrm{CD} 133 / \mathrm{CD} 44$ double positive cells and no visible tumor was formed in double negative cells over 2 months even in the mice to which 1,000 cells were injected (Table 2), which means 4 times higher tumorigenic activity has the CD133/CD44 double positive population compared to the unsorted cancer cells. The 

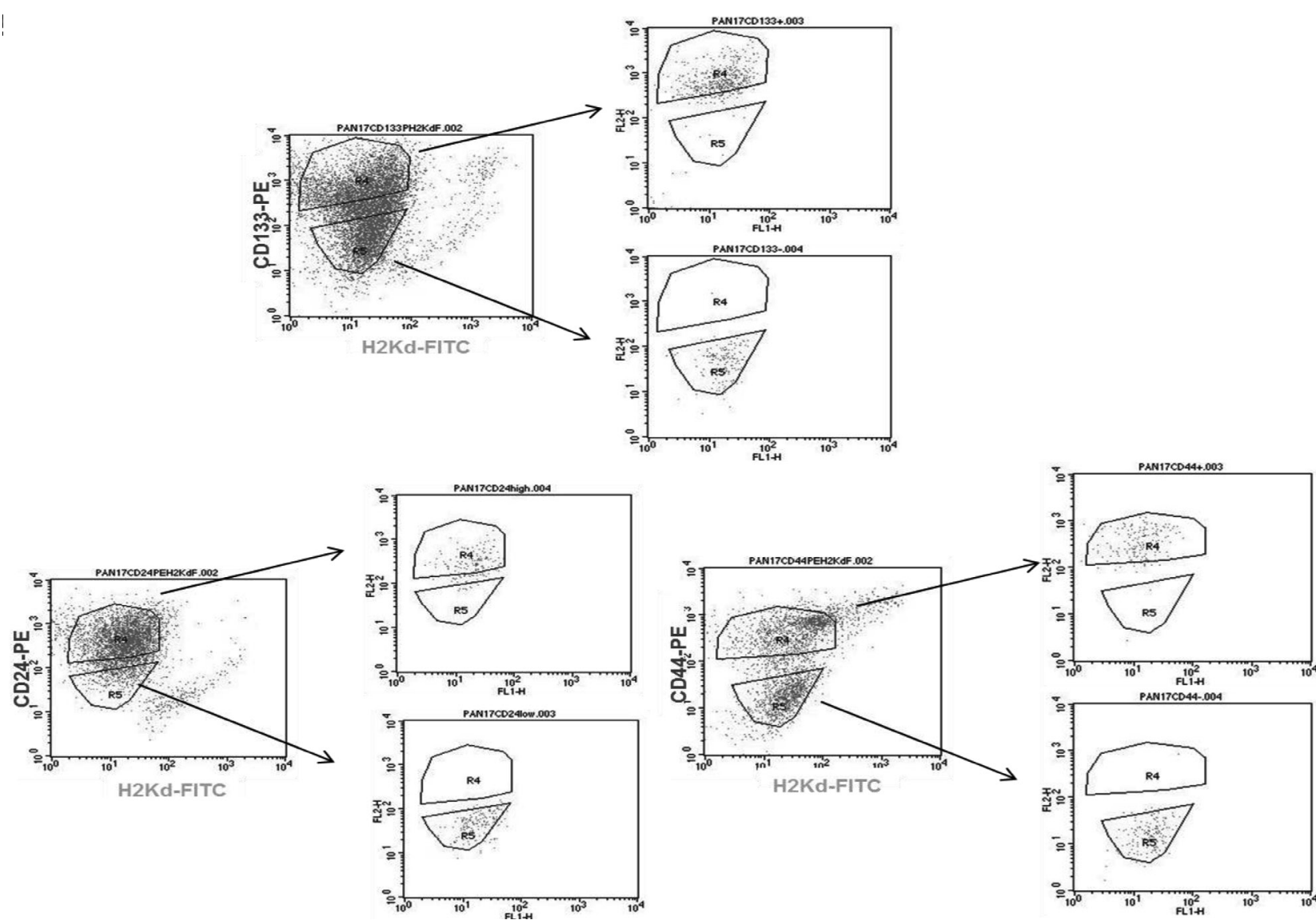

Figure 1: Expression of CD133 in PAN17 xenograft and purity of sorted cellular fraction, Flow cytometric dot plots demonstrating the heterogeneous expression of CD133 on cancer cells from the PAN-17-JCK xenograft tumor. R4 and R5 gates were set to separate CD133 positive and negative population respectively. The purity of each population was confirmed in 2nd FACS shown in the right windows. H2Kd positive cells are murine host stromal cells and eliminated in the cell sorting step.

putative frequency of tumor initiating cell was calculated according to the previously described method based on Poisson distribution [10]. The actual calculations were described in Supplemental Information 2.

\section{The gene signature of tumor initiating cells}

Gene expression profile in CD133/CD44 double positive population was compared to the double negative population and summarized in Table 3. According to gene functional analysis by Ingenuity Pathway Analysis, genes related to cell migration, cell survival, inflammatory response, free radical scavenge or amino acid metabolism were significantly changed between CSCs and non CSC fraction (Table 4). The genes upregulated more than 5 folds were compiled in Table 3. Significantly higher expression of EGF receptor (EGFR) ligand epiregulin (approx. 11-fold) and inflammatory cytokines CXCL8, also known as IL-8, and CXCL5, also known as ENA78 (approx. 8-fold) were observed in the CD133/CD44 double positive fraction. EGFR, CXCR1 and CXCR2, receptor for CXCL8 and CXCL5 respectively, were expressed in both of the CD133/CD44 double positive and the double negative fractions, suggesting important roles of their ligands in auto or paracrine fashion. The CSC markers reported in the literature [12] were listed in Supplemental Information Table 1 and compared to the expression profile of PAN17 CD133/CD44 double positive fraction. Some CSC markers such as ALDH1 or CD29 were accumulated in the PAN17 CD133/CD44 double positive CSC fraction.

\section{Gemcitabine treatment accumulates CSC fraction}

Cells were prepared from PAN-17-JCK xenografts after 5 times intraperitoneal injections of gemcitabine $(125 \mathrm{mg} / \mathrm{kg})$ in two weeks and thier cell surface expression of CD133 and CD44 were compared to those from untreated tumor tissues by FACS. The cellular population in CD133/CD44 double positive fraction was increased, while the double negative fraction decreased (Figure 3A). The clear correlation between gemcitabine resistance and CD133/CD44 expression was demonstrated. Thee indevendent experiments yielded statistically significant differences as described in Figure 3B.

\section{Discussion}

The pancreatic tumor initiating cell fractions were isolated from patient derived xenografts (PDXs) using FACS depending on the cell surface markers. Five out of six PDXs established from different pancreatic tumor patients were demonstrated to contain the cell populations which have high tumor initiating activity and were identified to have different cell surface marker profiles with limited consistency. This suggests that the cell surface markers of CSCs could be unique to individual patients and it might be difficult to specify the universal CSC markers shared among all pancreatic tumor patients. Although the cell surface properties of CSCs are different among the patients, intrinsic molecular mechanism of CSCs need to be analyzed and compared carefully to find out the common molecular 
Citation: Kashiwagi M, Tanaka H (2016) Identification of Cancer Stem Cells in Human Pancreatic Cancer, a Small Population with High Tumorigenic Activity and Chemotherapy Resistance. J Stem Cell Res Ther 6: 371. doi: 10.4172/2157-7633.1000371

Page 4 of 7

\begin{tabular}{|c|c|c|c|c|c|c|c|}
\hline & & PAN-04-JCK & PAN-12-JCK & PAN-08-JCK & PAN-17-JCK & PAN-06-JCK & PAN-02-JCK \\
\hline Marker & Injected cells & \multicolumn{6}{|c|}{ Tumor formation in NOD/scid s.c. } \\
\hline \multirow{4}{*}{ CD133(+) } & 1000 & 8 of 8 & 6 of 8 & 4 of 8 & 5 of 8 & 2 of 8 & \multirow{4}{*}{$\mathrm{N} / \mathrm{A}$} \\
\hline & 500 & 8 of 8 & 5 of 8 & 2 of 7 & 1 of 8 & 0 of 8 & \\
\hline & 250 & 6 of 8 & 3 of 8 & 0 of 8 & 1 of 8 & 0 of 8 & \\
\hline & 100 & 3 of 8 & 0 of 8 & 0 of 8 & 0 of 8 & 0 of 8 & \\
\hline \multirow{4}{*}{ CD133(-) } & 1000 & 7 of 8 & 2 of 8 & 1 of 8 & 0 of 8 & 0 of 8 & \multirow{4}{*}{ N/A } \\
\hline & 500 & 7 of 8 & 1 of 8 & 0 of 8 & 0 of 8 & 0 of 8 & \\
\hline & 250 & 7 of 8 & 2 of 8 & 1 of 8 & 0 of 8 & 0 of 8 & \\
\hline & 100 & 2 of 7 & 0 of 8 & 0 of 8 & 0 of 8 & 0 of 8 & \\
\hline \multirow{4}{*}{ CD24(+) } & 1000 & 6 of 8 & 8 of 8 & 4 of 8 & 4 of 8 & 2 of 8 & \multirow{4}{*}{ N/A } \\
\hline & 500 & 4 of 8 & 8 of 8 & 2 of 8 & 3 of 8 & 0 of 8 & \\
\hline & 250 & 4 of 7 & 8 of 8 & 3 of 8 & 1 of 8 & 0 of 8 & \\
\hline & 100 & 3 of 8 & 3 of 8 & 2 of 8 & 0 of 8 & 0 of 8 & \\
\hline \multirow{4}{*}{ CD24(-) } & 1000 & 8 of 8 & 7 of 8 & 4 of 8 & 1 of 8 & 0 of 8 & \multirow{4}{*}{$\mathrm{N} / \mathrm{A}$} \\
\hline & 500 & 6 of 8 & 6 of 8 & 3 of 8 & 1 of 8 & 0 of 8 & \\
\hline & 250 & 6 of 8 & 3 of 8 & 1 of 8 & 0 of 8 & 0 of 8 & \\
\hline & 100 & 3 of 8 & 1 of 8 & 0 of 8 & 1 of 8 & 0 of 8 & \\
\hline \multirow{4}{*}{ CD44(+) } & 1000 & 8 of 8 & 8 of 8 & 5 of 8 & 5 of 8 & 3 of 8 & 0 of 8 \\
\hline & 500 & 6 of 8 & 8 of 8 & 2 of 8 & 1 of 8 & 0 of 8 & 1 of 8 \\
\hline & 250 & 3 of 8 & 4 of 8 & 3 of 8 & 2 of 8 & 0 of 8 & 0 of 8 \\
\hline & 100 & 2 of 7 & 3 of 8 & 1 of 8 & 0 of 8 & 0 of 8 & 0 of 8 \\
\hline \multirow{4}{*}{ CD44(-) } & 1000 & 5 of 8 & 7 of 8 & 3 of 8 & 0 of 8 & 0 of 8 & 4 of 7 \\
\hline & 500 & 5 of 8 & 8 of 8 & 3 of 8 & 0 of 8 & 0 of 8 & 4 of 8 \\
\hline & 250 & 2 of 6 & 4 of 6 & 1 of 8 & 0 of 6 & 0 of 8 & 1 of 7 \\
\hline & 100 & 0 of 8 & 1 of 8 & 0 of 8 & 0 of 8 & 0 of 8 & 0 of 8 \\
\hline \multirow{3}{*}{ Unsorted } & 1000 & 6 of 8 & 2 of 8 & 1 of 8 & 2 of 8 & 1 of 8 & 0 of 8 \\
\hline & 500 & 3 of 8 & 1 of 8 & 2 of 8 & 1 of 8 & 0 of 8 & 0 of 8 \\
\hline & 250 & 5 of 8 & 2 of 8 & 0 of 8 & 0 of 8 & 0 of 8 & 0 of 8 \\
\hline
\end{tabular}

Table 1: In vivo limiting dilution assay of pancreatic cancer cells derived from human pancreatic cancer PDX.

A
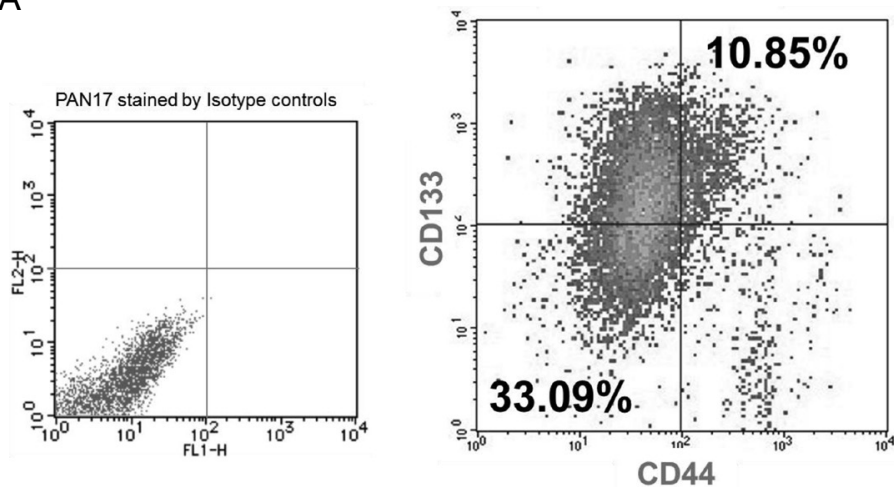

B

PAN-04-JCK

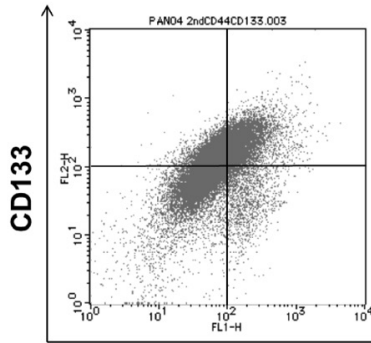

PAN-06-JCK

PAN-12-JCK
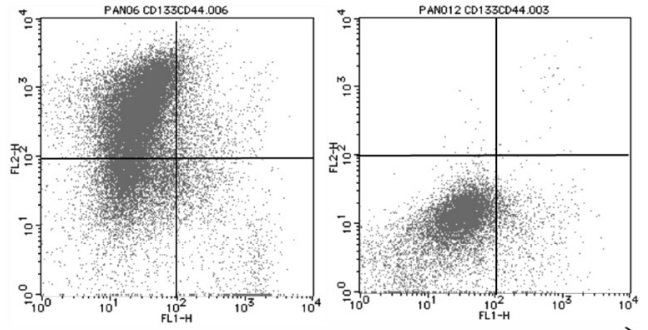

CD44

Figure 2: Expression of CD133 and CD44 on PAN-17-JCK derived cancer cells and other PDX derived cells. Cancer cells derived from PAN17 xenograft were stained by anti-CD133-PE conjugated antibody and anti-CD44-FITC conjugated antibody and subjected to FACS sorting. The rates of CD133/CD44 double positive and double negative populations were indicated as $10.85 \%$ and $33.09 \%$ respectively (A). Data from the other PDXs such as PAN-04-JCK, PAN-06-JCK and PAN-12-JCK were also shown below as comprison (B). 
Citation: Kashiwagi M, Tanaka H (2016) Identification of Cancer Stem Cells in Human Pancreatic Cancer, a Small Population with High Tumorigenic Activity and Chemotherapy Resistance. J Stem Cell Res Ther 6: 371. doi: 10.4172/2157-7633.1000371

Page 5 of 7

\begin{tabular}{|c|c|c|}
\hline \multirow{3}{*}{ Fraction } & Injected cell & Tumor formation in NOD/scid mice \\
\cline { 2 - 3 } CD133(-)/CD44(-)t & 1000 & 0 of 8 \\
\cline { 2 - 3 } & 500 & 0 of 7 \\
\cline { 2 - 3 } & 250 & 0 of 8 \\
\hline \multirow{4}{*}{ CD133(+)/CD44(+) } & 100 & 0 of 6 \\
\cline { 2 - 3 } & 1000 & 7 of 8 \\
\cline { 2 - 3 } & 500 & 4 of 8 \\
\hline \multirow{3}{*}{ Unsorted } & 250 & 2 of 7 \\
\cline { 2 - 3 } & 100 & 0 of 8 \\
\hline & 1000 & 3 of 7 \\
\cline { 2 - 3 } & 2500 & 0 of 8 \\
\hline
\end{tabular}

Table 2: Tumor initiating activity of CD133/CD44 double positive population.

\begin{tabular}{|c|c|c|c|}
\hline \multicolumn{2}{|c|}{ Up-regulated } & \multicolumn{2}{c|}{ Down-regulated } \\
\hline Molecules & Fold change & Molecules & Fold change \\
\hline EREG & 11.18 & ARL17A/ARL17B & -4.47 \\
\hline CXCL8 & 8.58 & ANKRD20A4 & -4.31 \\
\hline CXCL5 & 8.04 & RUNX1T1 & -4.05 \\
\hline RSAD2 & 7.76 & MEGF10 & -3.95 \\
\hline CALB1 & 7.45 & ZNF718 & -3.93 \\
\hline TOR1AIP1 & 7.01 & HBA1/HBA2 & -3.85 \\
\hline MAD2L1 & 6.84 & SCARNA2 & -3.76 \\
\hline HIBADH & 6.83 & EID2B & -3.61 \\
\hline PBRM1 & 6.79 & COL27A1 & -3.6 \\
\hline PPTC7 & 6.63 & SCARNA17 & -3.6 \\
\hline
\end{tabular}

Table 3: Genes up/down-regulated in PAN-17-JCK CD133/CD44 double positive fraction. mechanisms which support CSC key properties. In our report the CSC marker gene expression profile of the CD133/CD44 double positive CSCs recovered from PAN-17-JCK pancreatic cancer PDX was not fully consistent with that of all the pancreatic or other CSCs (SI Table 1). The comprehensive study in larger number of patients will be required to demonstrate statistically significant correlation between CSC markers and tumorigenic activity. In order to collect the cancer cells from the larger patient population, peripheral blood mononuclear cells (PBMCs) from tumor patients would be practical materials to be subjected to further analysis. As an example, circulating tumor cells (CTCs) purified as a CD45 negative and CD44 positive fraction were demonstrated to have high tumorigenic activity in NOD/scid mice and identified as CSCs in metastatic gastric cancer patients [13].

Three secreted ligand genes, epiregulin, CXCL8, and CXCL5 were expressed significantly higher in CSCs than in non-CSCs (Table 3). It is noteworthy that these growth factor and cytokines may exert their biological activities not only in CSCs themselves in autocrine fashion but also in host stromal cells through paracrine one. Epiregulin, a member of epidermal growth factor receptor (EGFR) ligand family, binds to EGFR/ErbB1, and ErbB4 receptors. Gene mutations, amplifications, and aberrant expression of EGFR family genes have been reported in a variety of cancer and play a key role in the growth and survival of cancer cells in malignant status [14]. Epiregulin-induced EGFR activation is essential for induction of cell migration and invasion by stabilizing Snail and Slug which promote EMT and metastatic features [15]. CXCL8 and CXCL5 belong to the inflammatory chemokine family and their receptors are CXCR1 and CXCR2 for CXCL8, and CXCR2 for CXCL5. The role of CXCL8 as a chemoattractant and activator of neutrophil and as an angiogenic molecule has been well investigated so far, although, its cell autonomous roles have not been fully elucidated. Recently, however, a study of isolated and characterized

\section{Molecules in Network}

\begin{tabular}{|c|c|c|}
\hline Score & $\begin{array}{c}\text { Focus } \\
\text { Molecules }\end{array}$ & $\begin{array}{l}\text { Top Diseases and } \\
\text { Functions }\end{array}$ \\
\hline 35 & 18 & $\begin{array}{l}\text { Cellular movement, } \\
\text { hematological system } \\
\text { development and function, } \\
\text { immune cell trafficking }\end{array}$ \\
\hline 33 & 17 & $\begin{array}{l}\text { Nervous system } \\
\text { development and function, } \\
\text { cancer, neurological } \\
\text { disease }\end{array}$ \\
\hline 30 & 16 & $\begin{array}{l}\text { Cancer, endocrine system } \\
\text { disorders, gastrointestinal } \\
\text { disease }\end{array}$ \\
\hline 30 & 16 & $\begin{array}{l}\text { Molecular transport, cell } \\
\text { death and survival, cell } \\
\text { morphology }\end{array}$ \\
\hline 28 & 15 & $\begin{array}{l}\text { Developmental disorder, } \\
\text { skeletal and muscular } \\
\text { disorders, inflammatory } \\
\text { response }\end{array}$ \\
\hline 23 & 13 & $\begin{array}{l}\text { Free radical scavenging, } \\
\text { small molecule } \\
\text { biochemistry, cancer }\end{array}$ \\
\hline 19 & 11 & $\begin{array}{l}\text { Amino acid metabolism, } \\
\text { small molecule } \\
\text { biochemistry, cell death } \\
\text { and survival }\end{array}$ \\
\hline 2 & 1 & $\begin{array}{l}\text { Cardiovascular system } \\
\text { development and function, } \\
\text { cell cycle, embryonic } \\
\text { development }\end{array}$ \\
\hline
\end{tabular}

Table 4: GO enrichment analysis on CSC gene expression profile. 
A

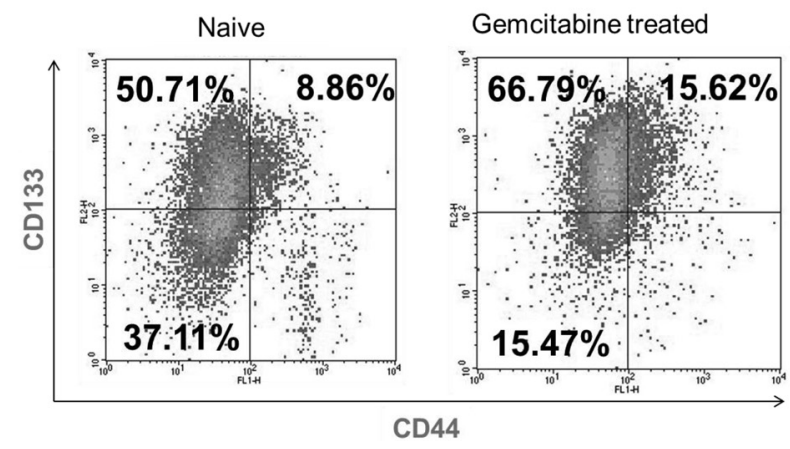

B

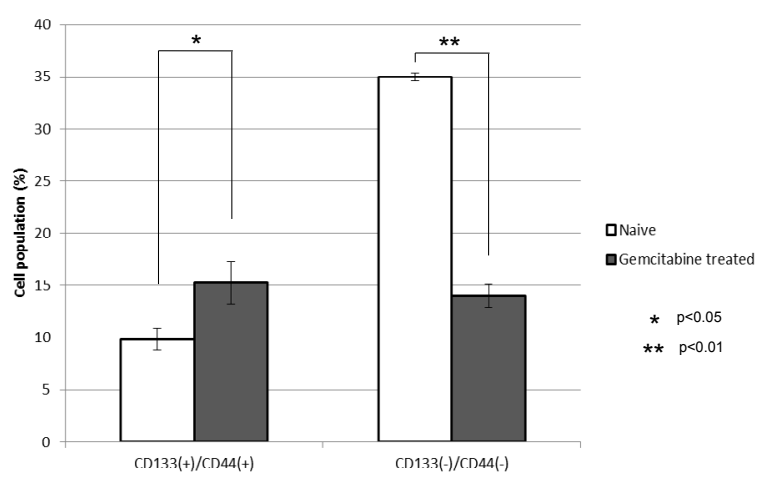

Figure 3: Change of CD133/CD44 expression profile of PAN17 xenograft derived cancer cells after gemcitabine treatment $\mathrm{CD} 133$ positive population was significantly increased after 2 weeks gemcitamine treatment $(125 \mathrm{mg} / \mathrm{kg}$ i.p. every 3 days), which indicates CD133 positive cancer cells could survive through the gemcitabine treatment. Especially CD133/CD44 double positive CSC fraction was increased more than 1.5 times (from $8.86 \%$ to $15.62 \%$ ) and concurrent significant reduction of CD133/CD44 double negative non CSC fraction was evident. Three independent experiments yielded statistically significant differeces in the cell populaitons as shown in a bar graph (B).

breast Cancer Stem Cells has revealed that CXCL8-CXCR1 axis has a role in promoting cancer stem cell self-renewal and invasion in vitro and in vivo [16]. In accordance with this notion, inhibition of CXCL8CXCR1/2 axis demonstrated significant suppression of breast cancer stem cell activity in vitro and in vivo $[17,18]$. Moreover, the expression of CXCR1 in human pancreatic ductal adenocarcinoma (PDAC) showed positive correlation with lymph node metastasis and a poor survival rate [19]. CXCL5 is considered to have cancer cell proliferating activity and also promote some angiogenesis through binding to CXCR2 expressed on endothelial cells and migrated neutrophils [20]. Blood vessels are indispensable components for every tissue to grow and survive, although, recent progress in stem cell research has revealed that they nurture CSCs as well as normal stem cells with niche cells by localizing in close proximity to the stem cells [21-23], indicating the important function of CXCL5-CXCR2 axis on stem cell maintenance. The expression of CXCL5 is, indeed, correlated with poor prognosis, suggesting the involvement of stem like cells in tumor progression. In other aspects the importance of NF-kB signaling pathway was indicated since the gene expression of epiregulin and CXCL8 are under control of NF-kB inflammatory signaling pathway [24]. The inflammation and tumor have been reported to be closely linked each other, it has been noted so far that mechanisms associated with inflammation play a part in tumor initiation and progression [25] and also associated with poor response to chemotherapy [26].

The biological function enrichment analysis was performed on the gene expression data with the tool program provided by Ingenuity Pathway Analysis (Table 4). The genes with changes more than twofold difference were picked up for the GO enrichment analysis. The GO category of "Cellular movement, Hematological system, Developmental function and Immune cell trafficking was indicated as significant by its highest score. The elevated gene signature related to "Cellular movement" is functionally relevant to the one of the important biological properties of CSCs' enabling formation of metastasis at distant sites. Enrichment in "Molecular transport, Cell death and survival, Cell morphology" and "Free radical scavenging, small molecule biochemistry, and Cancer" explains drug resistance of PAN-17-JCK CSC fraction to gemcitabine treatment. Actually gemcitabine treatment for PAN-17JCK xenografted mice resulted in the accumulation of CD133/CD44 double positive PAN-17-JCK CSC fraction (Figure 3A and 3B).

These data encourage the development of new therapeutic options that can target CSCs in combination with previously approved anticancer drugs for tumor treatment. EGFR has been recognized as an effective anti-cancer drug target and competitive drug development has given rise to several effective EGFR inhibitors such as gefitinib, erlotinib, lapatinib, cetuximab, and panitumumab. CXCR1 and CXCR2 were the drug targets for inflammatory diseases in earlier days and small inhibitor compound repertaxin [27] has been in clinical trial for prevention of delayed graft dysfunction after organ transplantation (NCT Identifier: NCT00248040). Repertaxin is in Phase II trial for metastatic triple negative breast cancer in combination with paclitaxcel (NCT Identifier: NCT02370238) and the clinical outcomes are being expected. We could propose new combination therapy using EGFR inhibitors, CXCR1/2 antagonists or CXCL8 antibody combined with first line therapy such as gemcitabine or nab-paclitaxcel for pancreatic cancer to achieve significant efficacy.

\section{Acknowledgements}

We thank Central Institute for Experimental Animals (Kawasaki, Japan) for providing patient derived pancreatic cancer xenografts, Nobuyuki Miyajima for gene expression data processing and Atsushi Nakanishi for supporting this research.

\section{Conflict of Interest}

Masahide Kashiwagi and Hideyuki Tanaka are employees of Takeda Pharmaceutical Company Limited. The authors declare no other conflict of interest associated with this manuscript.

\section{References}

1. Wicha MS, Liu S, Dontu G (2006) Cancer stem cells: an old idea--a paradigm shift. Cancer Res 66: 1883-1890. [PubMed]

2. Lapidot T, Sirard C, Vormoor J, Murdoch B, Hoang T, et al. (1994) A cell initiating human acute myeloid leukaemia after transplantation into SCID mice. Nature 367: $645-648$

3. Al-Hajj M, Wicha MS, Benito-Hernandez A, Morrison SJ, Clarke MF (2003) Prospective identification of tumorigenic breast cancer cells. Proc Natl Acad Sci USA 100: 3983-3988. [PubMed]

4. Singh SK, Clarke ID, Terasaki M, Bonn VE, Hawkins C, et al. (2003) Identification of a cancer stem cell in human brain tumors. Cancer Res 63 : 5821-5828. [PubMed]

5. Dalerba P, Dylla SJ, Park IK, Liu R, Wang X, et al. (2007) Phenotypic characterization of human colorectal cancer stem cells. Proc Natl Acad Sci USA 104: 10158-10163. [PubMed]

6. Kim CF, Jackson EL, Woolfenden AE, Lawrence S, Babar I, et al. (2005) Identification of bronchioalveolar stem cells in normal lung and lung cancer Cell 121: 823-835. [PubMed]

7. Collins AT, Berry PA, Hyde C, Stower MJ, Maitland NJ (2005) Prospective identification of tumorigenic prostate cancer stem cells. Cancer Res 65: 1094610951. [PubMed]

8. Bao S, Wu Q, McLendon RE, HaoY, ShiQ, et al. (2006) Glioma stem cells 
Citation: Kashiwagi M, Tanaka H (2016) Identification of Cancer Stem Cells in Human Pancreatic Cancer, a Small Population with High Tumorigenic Activity and Chemotherapy Resistance. J Stem Cell Res Ther 6: 371. doi: 10.4172/2157-7633.1000371

promote radioresistance by preferential activation of the DNA damage response. Nature 444: 756-760. [PubMed]

9. Ginestier C, Hur MH, Charafe-Jauffret E, Monville F, Dutcher J, et al. (2007) ALDH1 is a marker of normal and malignant human mammary stem cells and a predictor of poor clinical outcome. Cell Stem Cell 1: 555-567. [PubMed]

10. Li C, Heidt DG, Dalerba P, Burant CF, Zhang L, et al. (2007) Identification of pancreatic cancer stem cells. Cancer Res 67: 1030-1037. [PubMed]

11. Hermann PC, Huber SL, Herrler T, Aicher A, Ellwart JW, et al. (2007) Distinct populations of cancer stem cells determine tumor growth and metastatic activity in human pancreatic cancer Cell. Stem Cell 1: 313-323. [PubMed]

12. Medema JP (2013) Cancer stem cells: the challenges ahead. Nat Cell Biol 15: 338-344. [PubMed]

13. Toyoshima K, Hayashi A, Kashiwagi M, Hayashi N, Iwatsuki M, et al. (2015) Analysis of circulating tumor cells derived from advanced gastric cancer. Int J Cancer 137: 991-998. [PubMed]

14. ZaczekA, Brandt B, Bielawski KP (2005) The diverse signaling network of EGFR, HER2, HER3 and HER4 tyrosine kinase receptors and the consequences for therapeutic approaches. Histol Histopathol 20: 1005-1015. [PubMed]

15. Liu S, Ye D, Xu D, Liao Y, Zhang L, et al. (2016) Autocrine epiregulin activates EGFR pathway for lung metastasis via EMT in salivary adenoid cystic carcinoma. Oncotarget 7: 25251-25263. [PubMed]

16. Charafe-Jauffret E, Ginestier C, lovino F, Wicinski J, Cervera N, et al. (2009) Breast cancer cell lines contain functional cancer stem cells with metastatic capacity and a distinct molecular signature. Cancer Res 69: 1302-1313. [PubMed]

17. Ginestier C, Liu S, Diebel ME, Korkaya H, Luo M, et al. (2010) CXCR1 blockade selectively targets human breast cancer stem cells in vitro and in xenografts. J Clin Invest 120: 485-497. [PubMed]
18. Singh JK, Farnie G, Bundred NJ, Simoes BM, Shergill A, et al. (2013) Targeting CXCR1/2 significantly reduces breast cancer stem cell activity and increases the efficacy of inhibiting HER2 via HER2-dependent and -independent mechanisms. Clin Cancer Res 19: 643-656. [PubMed]

19. Chen L, Fan J, Chen H, Meng Z, Chen Z, et al. (2014) The IL-8/CXCR1 axis is associated with cancer stem cell-like properties and correlates with clinical prognosis in human pancreatic cancer cases. Sci Rep 4: 5911.

20. Li A, King J, Moro A, Sugi MD, Dawson DW, et al. (2011) Overexpression of CXCL5 is associated with poor survival in patients with pancreatic cancer. Am J Pathol 178: 1340-1349. [PubMed]

21. Nagahama Y, Ueno M, Miyamoto S, Morii E, Minami T, et al. (2010) PSF1, a DNA replication factor expressed widely in stem and progenitor cells, drives tumorigenic and metastatic properties. Cancer Res 70: 1215-1224. [PubMed]

22. Kiel MJ, Yilmaz OH, Iwashita T, Yilmaz OH, Terhorst C, et al. (2005) SLAM family receptors distinguish hematopoietic stem and progenitor cells and reveal endothelial niches for stem cells. Cell 121: 1109-1121. [PubMed]

23. Kiel MJ, Morrison SJ (2006) Maintaining hematopoietic stem cells in the vascular niche. Immunity 25: 862-864. [PubMed]

24. Li X, Massa PE, Hanidu A, Peet GW, Aro P, et al. (2002) IKKalpha, IKKbeta, and NEMO/IKKgamma are each required for the NF-kappa B-mediated inflammatory response program. J Biol Chem 277: 45129-45140. [PubMed]

25. Mantovani A, Allavena P, Sica A, Balkwill, F (2008) Cancer-related inflammation. Nature 454: 436-444. [PubMed]

26. Uwagawa T, Yanaga K (2015) Effect of NF-kappaB inhibition on chemoresistance in biliary-pancreatic cancer. Surg Today 45: 1481-1488. [PubMed]

27. Casilli F, Bianchini A, Gloaguen I, Biordi L, Alesse E, et al.(2005) Inhibition of interleukin-8 (CXCL8/IL-8) responses by repertaxin, a new inhibitor of the chemokine receptors CXCR1 and CXCR2. Biochem Pharmacol 69: 385-394. [PubMed] 